\title{
Anxiolytic effects of nicotine in a rodent test of approach-avoidance conflict
}

\author{
Ami Cohen • Robert W. Young • Miguel A. Velazquez • \\ Mariya Groysman • Kavon Noorbehesht • \\ Osnat M. Ben-Shahar • Aaron Ettenberg
}

Received: 13 March 2008 / Accepted: 31 January 2009 / Published online: 25 February 2009

(C) The Author(s) 2009. This article is published with open access at Springerlink.com

\begin{abstract}
Rationale Nicotine has been reported to produce both anxiolytic and/or anxiogenic effects in humans and animals. Objectives This study examined whether pretreatment with nicotine would alter anxiety in a unique runway model of approach-avoidance conflict.

Materials and methods Food-restricted rats were trained to run a straight alley once a day to obtain food upon goal-box entry. Beginning on trial 11, food reward was followed by a series of five foot shocks $(0.3-0.4 \mathrm{~mA}, 0.5 \mathrm{~s})$ in the goal box. Non-shocked control rats continued to run for food only. The resulting association of the goal box with both a positive (food) and negative (foot shock) stimulus produced an approach-avoidance conflict (subjects exhibited "retreat behaviors" in which they would approach the goal box, stop, and then retreat back towards the start box). Once retreats were established, their sensitivity to nicotine pretreatment $(0.0,0.03,0.045,0.06$, or $0.075 \mathrm{mg} / \mathrm{kg}$, i.v. $)$ was compared to saline. In subsequent tests, the effects of nicotine $(0.06$ or $0.03 \mathrm{mg} / \mathrm{kg}$ ) were examined on spontaneous activity (locomotion) and center-square entries in an open field (anxiety).

Results Doses of 0.06 and $0.075 \mathrm{mg} / \mathrm{kg}$, but not lower doses of nicotine, reduced the number of runway retreats, and $0.06 \mathrm{mg} / \mathrm{kg}$ nicotine increased the number of open-field center entries relative to saline. No effects on locomotion were observed.

Conclusions Nicotine reduced approach-avoidance conflict and increased the rats' willingness to enter the center of an
\end{abstract}

A. Cohen $\cdot$ R. W. Young $\cdot$ M. A. Velazquez $\cdot$ M. Groysman $\cdot$

K. Noorbehesht $\cdot$ O. M. Ben-Shahar $\cdot$ A. Ettenberg $(\bowtie)$

Behavioral Pharmacology Laboratory, Department of Psychology,

University of California,

Santa Barbara, CA 93106-9660, USA

e-mail: ettenberg@psych.ucsb.edu open field, suggesting that the drug can produce anxiolytic properties and that such effects may serve as an important factor in the persistence of smoking behavior.

Keywords Nicotine - Runway - Straight alley · Motivation · Anxiety $\cdot$ Conflict $\cdot$ Rat $\cdot$ Locomotor activity $\cdot$ Open field

\section{Introduction}

The maintenance of smoking behavior is generally thought to be a consequence of the primary psychoactive ingredient in tobacco smoke, i.e., nicotine (USDHHS 1988; Stolerman and Shoaib 1991; Di Chiara 2000). Research on the underlying neurobiological and behavioral factors responsible for nicotine self-administration have typically concentrated on the drug's positive reinforcing actions (e.g., Merlo Pich et al. 1999; Di Chiara 2000; Mansvelder and McGehee 2002). However, convergent lines of evidence now suggest an important role for the negative reinforcing properties of nicotine, e.g., its stress-reducing actions (e.g., Picciotto et al. 2002; Kassel et al. 2003; Baker et al. 2004; Feldner et al. 2007). For example, smoking behavior has been shown to increase during stressful tasks (McKennell 1970; Pomerleau and Pomerleau 1987; Perkins and Grobe 1992), and the presence of stress has long been thought to increase the risk of relapse in people who have stopped smoking (Daughton et al. 1990). Related to the impact of stress on smoking are suggestions that nicotine may in fact have anxiolytic (anti-anxiety) properties (e.g., Picciotto et al. 2002; Kassel et al. 2003). Tests of this notion, however, have yielded inconsistent results. In some human self-report studies, nicotine (but not nicotine-free tobacco) reduced both stress and anxiety (Pomerleau et al. 1984; Gilbert et al. 1989; Warburton and Mancuso 1998); however, in other studies, it 
had no such effect (Perkins et al. 1994; Herbert et al. 2001), and others have even reported that nicotine produced elevated levels of anxiety and negative affect (Newhouse et al. 1990; Foulds et al. 1997). Adding to the complexity of this issue is the fact that increased anxiety is a common symptom of smoking cessation (e.g., Hughes et al. 1991; Tate et al. 1993); hence, in the addicted smoker, the calming effects of nicotine consumption may represent the temporary relief of withdrawal symptoms (Parrott 2003) as opposed to an independent anxiolytic action.

Animal studies have also yielded somewhat inconsistent results when nicotine is delivered acutely to naïve subjects. For example, in research employing the elevated plus maze or the social interaction test, low doses of nicotine $(0.05-$ $0.4 \mathrm{mg} / \mathrm{kg}$, s.c. or i.p.) have been reported to have anxiolytic properties (e.g., Brioni et al. 1993; File et al. 1998; Irvine et al. 1999; Cheeta et al. 2001), while higher doses were demonstrated to produce anxiogenic effects (e.g., File et al. 1998; Ouagazzal et al. 1999; Cheeta et al. 2001; Balerio et al. 2006). Yet, others have reported anxiogenic actions of nicotine at doses as low as $1.0 \mathrm{mg} /$ kg, i.p. (e.g., Biala and Budzynska 2006; Biala and Kruk 2008). Moreover, nicotine has rarely been examined in the more prototypical behavioral screens for anxiolytic agents (i.e., approach-avoidance conflict tests). In the Vogel et al. (1971) or the Geller-Seifter test (Geller et al. 1962), an ongoing appetitive response (lever pressing for food or licking a spout for water) is reliably suppressed upon presentation of an aversive stimulus (e.g., mild shock) paired with reinforcer delivery. Drugs that effectively reduce this behavioral suppression are presumed to have anti-anxiety properties and in fact have proven to be effective anxiolytics in the human clinical population (e.g., Houser 1978; McCloskey et al. 1987; Vaidya et al. 2005). It was therefore of interest to assess the anxiolytic properties of nicotine in two procedurally different test paradigms, i.e., an operant runway model of approachavoidance conflict and an open-field test that assesses the animal's unconditioned fear of open spaces.

Previous work in our laboratory has demonstrated that food-deprived rats running a straight alley for food reinforcement will exhibit "conflict" about entering the goal box if the presentation of food is followed by aversive foot shock (Geist and Ettenberg 1997). In such studies, the dependent measure is not how much time it takes the animal to traverse the alley (i.e., run time) but rather the occurrence of approach-avoidance conflict that results from concurrent positive and negative associations that subjects have about goal-box entry. As originally suggested by Miller (1944), this conflict can be operationally defined by the frequency with which the animal approaches but then moves away from the goal box. We quantify this conflict through the measurement of "retreat behaviors," i.e., the number of times that an animal approaches the goal box, stops at the entry point, and then turns and retreats back toward the start box (e.g., Geist and Ettenberg 1997). In addition to food+shock experiments, retreat behaviors have also been shown to occur in animals running for drug reinforcers known to have mixed positive+negative consequences (e.g., cocaine; Ettenberg and Geist 1991, 1993; Geist and Ettenberg 1997; Guzman and Ettenberg 2004). Additionally, pretreatment with anxiolytic drugs dosedependently reduce retreat frequency in the runway, e.g., diazepam (Ettenberg and Geist 1991; Geist and Ettenberg 1997), alcohol (Knackstedt and Ettenberg 2005), heroin (Guzman and Ettenberg 2004), and buspirone, a partial 5HT(1A) agonist (Ettenberg and Bernardi 2006).

As indicated above, nicotine self-administration is thought to involve both positive and negative reinforcing properties. We have previously reported (Cohen and Ettenberg 2007) that animals will run an alley to earn i.v. injections of nicotine upon goal-box entry (i.e., positive reinforcement). In the current study, the effects of nicotine on approach-avoidance conflict were assessed in rats running for food paired with mild foot shock - a test of the drug's putative anxiolytic properties. Since there is no a priori reason to assume that the effective dose in the runway conflict test will be comparable to that required to sustain runway self-administration, the current study included one dose that supported runway self-administration $(0.03 \mathrm{mg} / \mathrm{kg}$, i.v. $)$, another that did not $(0.06 \mathrm{mg} / \mathrm{kg})$, and additional doses that bracketed these two (i.e., 0.045 and $0.075 \mathrm{mg} / \mathrm{kg}$ ). The intent was to determine whether or not i.v. nicotine doses shown to have different effects in a positive reinforcement test would produce a similar profile in an approachavoidance conflict test. Finally, to aid in the interpretation of the resulting data set, two additional tests were conducted: (a) To assess for possible non-specific psychomotor actions of nicotine (e.g., Clarke and Kumar 1983; Lee 1985; Dwoskin et al. 1999; Miller et al. 2003; Neugebauer et al. 2006), its effects on spontaneous locomotor activity were examined and (b) to ensure the validity of the runway approach-avoidance test, the effects of nicotine were also assessed in an open-field apparatus where anxiolytic drugs have been shown to reduce a rat's reluctance to enter the central open "unprotected" regions of a novel environment (e.g., Montgomery 1955; Prut and Belzung 2003).

\section{Materials and methods}

\section{Subjects}

Male Sprague-Dawley rats (300-350 g) from Charles River Laboratories (Wilmington, MA, USA) were individually housed in a temperature-controlled vivarium environment 
with food and water available ad libitum. Each animal was handled for 10 min daily for 1 week to minimize the effects of handling stress. The animals' care and all experimental procedures were reviewed and approved by the University of California at Santa Barbara's Institutional Animal Care and Use Committee for compliance with the National Institutes of Health Guide for the Care and Use of Laboratory Animals (1996).

\section{Surgery}

The surgical procedures used here were precisely as described previously (e.g., see Cohen and Ettenberg 2007). Briefly, anesthesia was induced by inhalation of isoflurane gas ( $4 \%$ for induction; $1.5-2.5 \%$ for maintenance) during which an i.v. jugular catheter (PE20) was implanted in each rat. During surgery, atropine $\left(0.02 \mathrm{mg} \mathrm{kg}^{-1} / 0.05 \mathrm{ml}\right.$, i.m.) was injected to prevent respiratory congestion, and the non-opiate analgesic, flunixin meglumine (Benamine, $2 \mathrm{mg} \mathrm{kg}^{-1} / 0.4 \mathrm{ml}$, s.c.) was provided for post-surgical pain. The open end of the catheter was passed s.c. to a threaded cannula (item 313G; Plastics One, Roanoke, VA, USA) exited through a small opening on the animal's back where it was secured in place with the use of Mersilene mesh. Following surgery, the antibiotic ticarcillin disodium and clavulantate potassium (Timentin; $50 \mathrm{mg}$ in $0.25 \mathrm{ml}$ of $0.9 \%$ physiological saline, i.v.) was injected i.v. followed by $0.1 \mathrm{ml}$ of heparin (66 IU/ $\mathrm{ml})$ to maintain catheter patency. Heparin and Timentin injections were repeated once each day for 1 week, after which a reduced dose of $10 \mathrm{mg}$ Timentin (in $0.1 \mathrm{ml}$ ) was injected daily throughout the rest of the experiment. The patency of catheters was confirmed once a week by assessing the loss of the righting reflex following a 1-mg i.v. injection of the fast-acting barbiturate sodium methohexital (Brevital; $1.0 \mathrm{mg}$ dissolved in $0.1 \mathrm{ml}$ nanopure water).

\section{Food restriction}

A restricted feeding protocol (approximately 15-20 g of food/day) was initiated 7-10 days after surgery to gradually reduce each rat's body weight to $90 \%$ of free-feeding values. Weights were then adjusted upwards each week in recognition of the normal growth pattern of male rats over time. All experimental trials were conducted between 0900 and 1400 hours each day and daily food rations were provided $1-3 \mathrm{~h}$ after each runway session.

\section{Drugs}

(-)-Nicotine hydrogen tartrate salt (Sigma, St Louis, MO, USA) was dissolved in a solution of $0.9 \%$ physiological saline whose $\mathrm{pH}$ was adjusted to $7.2-7.4$ by the addition of sodium hydroxide. On test day, rats were administrated with $0.0,0.03,0.045,0.06$, or $0.075 \mathrm{mg} / \mathrm{kg}$, i.v. nicotine (doses refer to free base) in a volume of $0.1 \mathrm{ml}$ delivered by a syringe/infusion pump (Razel) over a 4-s interval.

Operant runway conflict test

\section{Runway apparatus}

Trials were conducted in two identical wooden straight alley runways $(160 \mathrm{~cm} \mathrm{~L} \times 12 \mathrm{~cm} \mathrm{~W} \times 44 \mathrm{~cm} \mathrm{H})$. A start box and a goal box were located at opposite ends of the runway (each $23 \mathrm{~cm} \mathrm{~L} \times 20 \mathrm{~cm} \mathrm{~W} \times 44 \mathrm{~cm} \mathrm{H}$ ). Both start and goal boxes were separated from the alley by means of sliding doors. The runway floor consisted of small-diameter steel rods arranged perpendicular to the runway walls. A food trough was located on the rear wall inside the goal box for delivery of the food reinforcement (45 mg Noyes, pellets), and the goal box floor was wired to a Med Associates ENV 414 Shocker for the delivery of foot shock. The subject's location within the apparatus was detected in real time by 13 pairs of infrared photodetector-emitter pairs embedded in the walls and evenly spaced along the length of the runway ( $5 \mathrm{~cm}$ above the floor). The output of the infrared sensors was fed to a desktop PC running custom software (Hamilton-Kinder, San Diego, CA, USA). The computer also controlled the operation of the start/goal doors, the syringe pump, and data collection. The primary dependent measure in this work, as in previous studies of this kind (e.g., Knackstedt and Ettenberg 2005; Ettenberg and Bernardi 2006), was the number of retreat behaviors occurring on each trial prior to goal-box entry-an index that reflects the intensity of the subject's approach-avoidance conflict on a given trial. A "retreat" was operationally defined as a stop in forward locomotion followed by a return towards the start box of a distance equivalent to at least two infrared detectors (i.e., 30-cm distance); in practice, however, we observed that once an animal stops and turns away from the goal box, it invariably retreats all the way back to the start box. In addition to retreat frequency, we also measured each animal's run time on every trial (the time to enter the goal box once a rat had left the start box). Since run times would be expected to change somewhat as a function of changes in retreat behaviors (i.e., rats that exhibit more back and forth behavior in the alley will obviously take longer to enter the goal box than rats that exhibit fewer retreats; see discussion by Ettenberg and Geist 1991), we expected this measure to somewhat mirror any observed changes in retreats that might be produced by nicotine.

\section{Runway procedure}

Phase 1: food training All rats were trained to traverse the runway for food reinforcement over a 10-day period during 
which each animal experienced a single trial per day. Each rat was placed into the start box for $10 \mathrm{~s}$ after which the start box door opened and the animal was permitted to travel the length of the alley and enter the goal box. The detection of the animal in the goal box (by infrared sensors) signaled the computer to close the goal door, after which ten $45-\mathrm{mg}$ food pellets were immediately delivered into the food trough. Rats were provided $3 \mathrm{~min}$ to consume the food after which they were returned to their home cages. On the occasional trial when an animal did not enter the goal box within $15 \mathrm{~min}$, it was gently maneuvered into the goal box by the experimenter.

Phase 2: food + shock training Beginning on the 11th day of runway testing, the delivery of the food reinforcer was followed $1.5 \mathrm{~min}$ later by a series of five 0.5 -s foot shocks (0.3-0.4 mA in intensity and delivered one per second). After $1.5 \mathrm{~min}$ upon termination of the foot shock, the rat was removed from the goal box and returned to its home cage. Testing continued in this manner-one trial per dayuntil a given subject met a stable performance criterion of at least three retreats per day on three out of four consecutive days (requiring between 14 and 28 days/trials for different animals). Once this criterion was reached for a given subject, it was randomly assigned to one of the three nicotine dose conditions (see below) and tested in phase 3 of the experiment. An additional group of rats served as non-shock controls and continued to earn food (without foot shock) throughout the second phase of the experiment.

Phase 3: nicotine challenge Once a rat had reached criterion performance in phase 2 (i.e., exhibited stable levels of approach-avoidance retreats over trials), it underwent a 2day test procedure. On the first day, each animal was pretreated with a single 4-s i.v. injection of $0.1 \mathrm{ml} 0.9 \%$ physiological saline $10 \mathrm{~min}$ prior to a single food + shock runway trial. This provided a baseline against which a subsequent nicotine challenge could be compared. Note that three animals did not exhibit the minimum three retreats on baseline day and hence were removed from the study, the logic being that there needed to be sufficient "conflict" on the baseline trial against which to assess the effects of nicotine. On the next day, each rat was pretreated $10 \mathrm{~min}$ prior to runway testing with one of five doses of i.v. nicotine: $0.0(n=$ $8), 0.03(n=7), 0.045(n=6), 0.06(n=7)$, or $0.075 \mathrm{mg} / \mathrm{kg}$ $(n=7)$. The non-shocked control group $(n=10)$ received saline on the first day (baseline) and then a dose of $0.06 \mathrm{mg} /$ $\mathrm{kg}$ (test) prior to non-shocked food-reinforced runway trials.

\section{Locomotor activity}

An additional set of rats $(n=24)$ was used to assess whether or not changes in runway performance could be accounted for by simple nonspecific changes in spontaneous locomotor activity. The apparatus consisted of 12 identical Hamilton-Kinder Plexiglas locomotor chambers (each $22 \mathrm{~cm} \mathrm{~W} \times 44 \mathrm{~cm} \mathrm{~L} \times 20 \mathrm{~cm} \mathrm{H}$ ). Intravenous catheterized rats were individually placed into a chamber for $30 \mathrm{~min}$ (baseline), removed and injected with one of three doses of i.v. nicotine $(0.0,0.03,0.06 \mathrm{mg} / \mathrm{kg} ; n=8 /$ group $)$, and then replaced (10 min post-injection) into the chambers for an additional $30 \mathrm{~min}$ beginning $10 \mathrm{~min}$ post-injection. Note that the treatment regimen intentionally included a dose that effectively attenuated approach-avoidance conflict in the runway $(0.06 \mathrm{mg} / \mathrm{kg})$ and another that did not $(0.03 \mathrm{mg} / \mathrm{kg})$. The 10-min post-injection delay was instituted to ensure comparability with the runway experiment. Infrared photocell emitter-detector pairs lined the interior of the apparatus and provided data to a PC running custom software ("Motor Monitor" by Hamilton-Kinder) that converted the beam interruptions into a measure of total distance traveled (in centimeters).

\section{Open-field test}

Another set of i.v. catheterized rats $(N=24)$ was randomly assigned to one of three groups (corresponding to different doses of i.v. nicotine) and assessed for their propensity to enter the center squares of an open-field apparatus. The apparatus consisted of two identical large square enclosures (each $120 \mathrm{~cm} \mathrm{W \times 130} \mathrm{cm} \mathrm{L \times 40} \mathrm{cm} \mathrm{H)} \mathrm{the} \mathrm{floors} \mathrm{of} \mathrm{which}$ were each divided into sixteen $30-\mathrm{cm}$ square regions: four central squares and 12 squares along the periphery. Testing was conducted under low light conditions (two 30-W red lights). Each rat was injected with a single dose of i.v. nicotine $(0.0,0.03,0.06 \mathrm{mg} / \mathrm{kg}$; six to eight rats/group) and then placed into one of the corners of the apparatus starting 10 min post-injection. An observer (blind to the rat's group assignment) recorded the total number of entries into each square in the apparatus over a single 10 min test session. An entry was recorded when all four of the rat's paws were within a single square.

\section{Results}

Anti-conflict effects of nicotine in the runway conflict test

The effects of i.v. nicotine pretreatment on the retreat behavior of animals running to a goal box associated with both food and shock are depicted in Fig. 1. A two factor (group $\times$ trial) analysis of variance (ANOVA) computed on the retreat data revealed no main effect of group but did yield a statistically significant effect of trial $[F(1,30)=5.91$, $p<0.05]$, confirming that when averaged across all groups, the frequency of retreat behaviors on nicotine test days was 
different than that produced on baseline days. Of particular relevance to the current study was a statistically significant group $\times$ trial interaction $[F(4,30)=2.8, p<0.05]$ indicating that the change in behavior from baseline to test differed for the five treatment groups. Indeed, as can be clearly seen in Fig. 1, only the three highest doses of nicotine reduced retreat behaviors on test day relative to baseline. Post hoc analyses (simple one-tailed repeated measures $t$ tests) confirmed that retreats exhibited by the 0.06 and $0.075 \mathrm{mg} / \mathrm{kg}$ groups were reliably lower on test day compared to baseline ( $p<0.01$ and 0.05 respectively), while the 0.045 group failed to reach statistical significance $(p>0.05)$.

The run times of nicotine-treated animals mirrored the effects observed on retreats, although these changes approached but did not reach statistical significance. On test day, rats treated with $0.0,0.03,0.045,0.06$, or $0.075 \mathrm{mg} / \mathrm{kg}$ nicotine, respectively, entered the goal box in $418.8 \pm 125.6,276.7 \pm 74.6,345.4 \pm 129.4,110.5 \pm 32.9$, and $288.6 \pm 109.1 \mathrm{~s}$. Thus, the animals with the fastest run times (the 0.06 group) also made the fewest retreats, while the animals in the two slowest groups (the 0.0 and 0.03 groups) made the most retreats on test day. Additionally, as was the case with retreats, the only groups to demonstrate shorter run times on test day relative to baseline were the 0.06 and $0.075 \mathrm{mg} / \mathrm{kg}$ groups. Note that we have not included in the figure the data from non-shock control subjects $(n=10)$ running only for food reinforcement since these animals exhibited no retreat behaviors either in the presence or absence of $0.06 \mathrm{mg} / \mathrm{kg}$, i.v. nicotine. Addition-

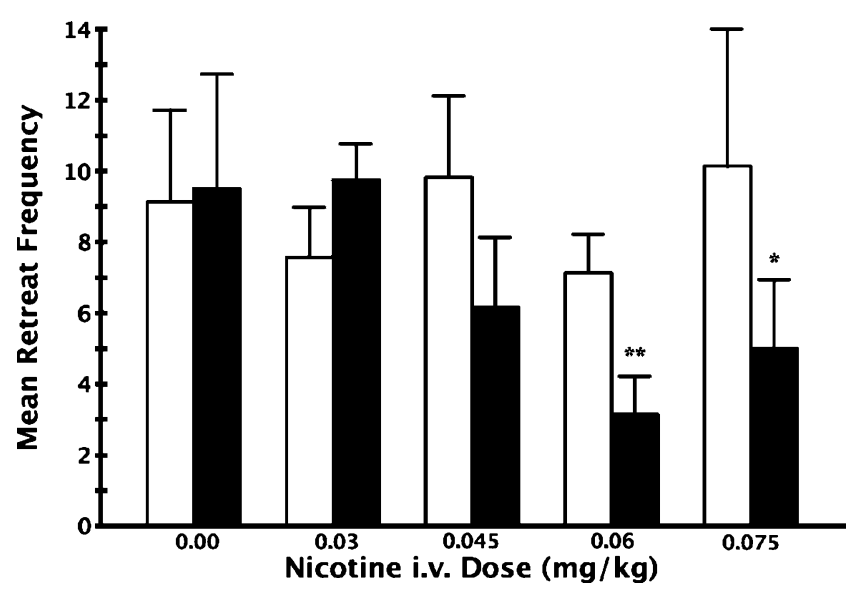

Fig. 1 Mean (+SEM) effects of nicotine on the total number of retreats emitted by rats running a straight alley for food+foot shock. Each of the five dose conditions were conducted in different groups of subjects tested first on a non-treatment baseline (white bars) followed by a test day (dark bars) in which their designated treatment $(0.0$, $0.03,0.045,0.06$, or $0.075 \mathrm{mg} / \mathrm{kg}$, i.v.) was administered $10 \mathrm{~min}$ prior to testing. Retreats were reliably lower on test day compared to baseline for the two high dose groups; ${ }^{*} p<0.01,{ }^{*} p<0.05$

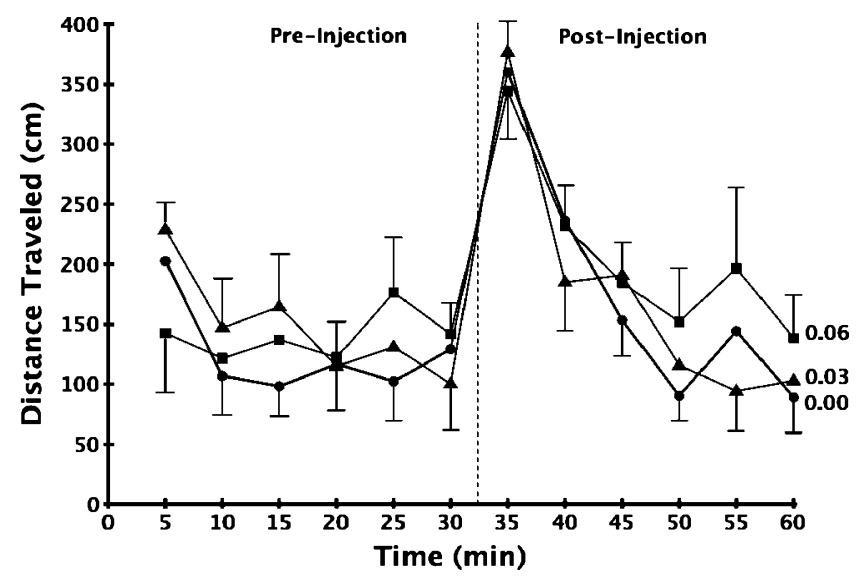

Fig. 2 Mean (+SEM) locomotor activity for three groups of rats during the $30 \mathrm{~min}$ prior to and the $30 \mathrm{~min}$ after injection with one of three doses of i.v. nicotine $(0.0,0.03$, or $0.06 \mathrm{mg} / \mathrm{kg})$. The data are expressed as "distance traveled" in centimeters during each 5-min period. The vertical dotted line represents the point at which the animals were removed, injected, and then replaced into the locomotor activity apparatus $10 \mathrm{~min}$ later

ally, the run times of these subjects did not significantly differ between baseline $(8.47 \pm 3.46)$ and test $(7.59 \pm 2.56)$ trials and were thus not reduced by nicotine pretreatment.

\section{Locomotor activity}

Figure 2 depicts the mean $( \pm \mathrm{SEM})$ locomotor activity (distance traveled) of each group during the pre-injection baseline and following treatment with $0.0,0.03$, or $0.06 \mathrm{mg} /$ $\mathrm{kg}$ nicotine, i.v. Separate two-factor (group $\times$ time) ANOVAs were computed on the pre-injection and post-injection data shown in the figure. Both ANOVAs revealed statistically significant effects of time [pre-injection: $F(5,105)=2.52, p<$ 0.05 ; post-injection: $F(5,105)=26.96, p<0.01]$, confirming that on average, animals tended to slow their locomotion as time progressed (a common pattern in locomotor activity studies as the animals habituate to the test environment). The effect of "time" was particularly pronounced during the postinjection period where an initial "spike" in activity was undoubtedly a consequence of the disruption (and resulting arousal) caused by the removal of the animals and administration of the i.v. injections. There were, however, no group differences in locomotor activity nor a group $x$ time interaction either before or after i.v. injections. Hence, acute i.v. nicotine at the doses examined did not alter the unconditioned spontaneous locomotion of treated animals.

\section{Open-field test}

While nicotine had no significant effect on the absolute number of squares entered in the open field, the proportion of total entries that rats made into the center squares was reliably increased in the high- but not the low-dose group. 
The mean $( \pm$ SEM) total number of squares entered by the $0.0,0.03$, and 0.06 dose/groups were, respectively, $138.38 \pm$ $12.8,144.44 \pm 9.87$, and $132.71 \pm 10.65$ (one-factor independent group ANOVA, $p>0.05)$. Entries into the center squares of the open field (expressed as a proportion of total entries) are depicted in Fig. 3. A one-factor ANOVA computed on those data revealed a statistically significant group difference $[F(2,21)=3.604, p<0.05]$, with Bonferroni post hoc tests confirming that the $0.06 \mathrm{mg} / \mathrm{kg}$ group performed differently (exhibited a greater proportion of center entries) than both the $0.03-$ and $0.0-\mathrm{mg} / \mathrm{kg}$ groups $(p<0.05)$.

\section{Discussion}

The aim of the present study was to investigate the putative anxiolytic effects of i.v. nicotine using a runway conflict procedure. Food-restricted rats running a straight alley for food+foot shock approached the goal box normally but then hesitated about entering and tended to retreat back toward the start box. This same behavioral paradigm was first employed by Miller (1944) who described the animals' behavioral ambivalence about goal-box entry as a form of approach-avoidance conflict. More recently, Geist and Ettenberg (1997) substantiated this conclusion by objectively counting the frequency of retreat behaviors in the alley and then demonstrating that these behaviors could be dose-dependently attenuated by administration of the anxiolytic agent, diazepam. In the current study, pretreatment with 0.06 and 0.075 but not 0.03 or $0.045 \mathrm{mg} / \mathrm{kg}$, i.v. nicotine similarly reduced the number of retreats in rats running toward a goal box associated with both food and foot shock (see Fig. 1). This is not meant to suggest that nicotine and diazepam have equivalent anxiolytic potency.

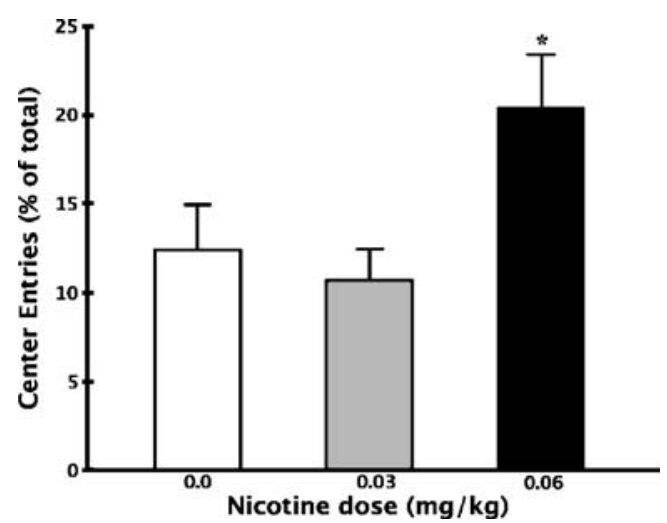

Fig. 3 Open-field performance during a 10-min test for three groups of rats pretreated with differing doses of i.v. nicotine. The data represent group mean $(+\mathrm{SEM})$ center-square entries expressed as a percentage of total squares entered. ${ }^{*} 0.06-\mathrm{mg} / \mathrm{kg}$ group was statistically different from each of the other two groups $(p<0.05)$
Indeed, while diazepam reduced both retreats and run times in our earlier study (Geist and Ettenberg 1997), the effect of nicotine on run time in the current study did not reach statistical significance $(p=0.098)$. Nevertheless, the subjects' pattern of responding in the runway remains consistent with the hypothesis that nicotine can act to reduce approach-avoidance conflict and hence may have anxiolytic actions. Such actions could, of course, account for some of the increases in self-administration that occur in human smokers during stressful or high anxiety contexts (McKennell 1970; Pomerleau and Pomerleau 1987; Perkins and Grobe 1992) and related reports among smokers that the drug helps individuals relax or feel calmer during periods of stress or anxiety (Pomerleau et al. 1984; Gilbert et al. 1989; Nichter et al. 1997).

Given the rate-independent nature of retreats (i.e., treatments that simply slow or activate the animal would not in and of themselves be expected to alter stop-and-retreat behaviors), it is difficult to account for the nicotine-induced changes in runway retreat behavior by non-specific psychomotor actions of the drug. Indeed, 0.03 and $0.06 \mathrm{mg} / \mathrm{kg}$, i.v. nicotine (i.e., a dose that had no impact on retreat behaviors and another that reliably reduced retreat frequency) neither increased spontaneous locomotion (Fig. 2) nor altered the absolute number of squares crossed in an openfield test. Additionally, while $0.06 \mathrm{mg} / \mathrm{kg}$, i.v. nicotine significantly reduced the number of retreats in rats receiving food + shock, it did not affect the run times of the non-shocked control group. While such findings would appear to contradict the common classification of nicotine as a psychomotor stimulant, in point of fact, the conditions under which nicotine produces increases in unconditioned locomotion are complex and variable. For example, some studies have reported that acute nicotine causes an initial suppression of activity followed subsequently by a stimulatory effect (Clarke and Kumar 1983; Ksir 1994; Miller et al. 2001; Neugebauer et al. 2006), while other studies using comparable nicotine doses have demonstrated a stimulatory effect without a preceding suppressive phase (Tessari et al. 2004), or no effect at all (Shram et al. 2006). Additionally, of the handful of studies that have employed an i.v. route of administration (using doses similar to those employed in the current research), one reported increased locomotion in female rats (Samaha et al. 2005), two studies observed no significant effects in male rats (Booze et al. 1999; Harrod et al. 2004), and one described a modest decrease in activity during the first few minutes post-injection (Cao et al. 2007). This inconsistency in the published findings motivated us to directly assess the locomotor effects of nicotine using the two intermediate doses employed in the runway (i.e., 0.03 and $0.06 \mathrm{mg} / \mathrm{kg}$, i.v.) and using the same post-injection time frame (testing $10 \mathrm{~min}$ after nicotine administration). As indicated above, we found no changes in nicotine-induced 
spontaneous unconditioned locomotion that could account for the drug's putative anti-conflict effects in the runway.

Consistent with the view that the $0.06-\mathrm{mg} / \mathrm{kg}$, i.v. dose of nicotine had anxiolytic actions in the runway was the demonstration that it increased the willingness of treated animals to enter into the center region of a novel open field (Fig. 3). When placed into novel open fields, rats normally exhibit thigmotaxis - i.e., a strong tendency to remain close to the walls of the apparatus - an effect that is thought to reflect an inherent fear of open unprotected spaces (Walsh and Cummins 1976; Treit and Fundytus 1988; Prut and Belzung 2003). Drugs that reduce anxiety in humans (e.g., anxiolytics) increase the proportion of center entries relative to total entries (e.g., Montgomery 1955; Prut and Belzung 2003), as did the $0.06-\mathrm{mg} / \mathrm{kg}$ (but not the $0.03 \mathrm{mg} / \mathrm{kg}$ ) dose of nicotine in the current study. Thus, when taken together, the results of the runway and open-field tests strongly support the contention that acute nicotine administration can have statistically reliable anxiolytic actions in laboratory animals and that such actions are not restricted to drugdependent animals in which the nicotine is merely reducing the anxiety and stress associated with the onset of withdrawal (e.g., see Parrott 2003).

The current results are of course consistent with those of prior studies reporting anxiolytic effects of non-i.v. nicotine (e.g., Brioni et al. 1993; Irvine et al. 1999; Cao et al. 2007), while remaining in contrast to those reports suggesting neutral or even anxiogenic effects of the drug (e.g., Morrison 1969; Glowa 1986; Balerio et al. 2006; Biala and Budzynska 2006). This should not be particularly surprising given the differences in the drug doses, routes of administration, and experimental procedures between the various studies. Indeed, in the earliest work on nicotine, Goldberg and Spealman (1983) demonstrated that the same doses of nicotine that were self-administered in one experiment could serve as punishments and suppress lever pressing under a fixed-ratio schedule of food presentation. While we cannot therefore offer an explanation that would account for the discrepancies in all of these published reports, we do note two important and relatively unique features of the current work: First, unlike the vast majority of such studies, we have employed an i.v. route of drug administration rather than applying the nicotine s.c. or i.p. Our intent was to effectively model the relatively fast delivery of nicotine that occurs with human smokers and to use a route of administration that delivers a reliable and constant dose of nicotine across animals. Subcutaneous and i.p. routes of administration are methodologically easy to conduct but produce highly variable and relative slow rates of drug absorption that necessarily weaken the comparability to the human condition. Second, unlike the majority of previous animal studies of nicotine's putative anxiolytic effects (i.e., those employing the social interaction test or elevated plus maze), the current runway conflict test uses a methodology that is much more akin to the prototypical behavioral screens for anxiolytic agents, such as the Vogel test or the Geller-Seifter test. In such tests, the animals' responding for a positive stimulus (e.g., food) is altered by contingent presentation of a negative stimulus (shock), the effects of which can be reversed by pretreatment with anxiolytic agents (Houser 1978; McCloskey et al. 1987; Vaidya et al. 2005). To our knowledge, the current results are the first to demonstrate an anxiolytic effect of i.v. nicotine using this type of approach-avoidance conflict test.

Together, the data from the current three experiments strengthen the view that the motivation to seek nicotine is derived from its ability to produce not only positive but also negative reinforcement (via the drug's anxiolytic actions). The doses employed in this study were derived from our previous work where animals exhibited faster running over trials for goal-box entry that was reinforced by i.v. administration of a single injection of $0.03 \mathrm{mg} / \mathrm{kg}$ nicotine each day/trial (Cohen and Ettenberg 2007). This same dose has also been reported to support lever press i.v. selfadministration in other studies (Corrigall and Coen 1989; Donny et al. 1995; Watkins et al. 1999; De noble and Mele 2006). We note, however, that $0.03 \mathrm{mg} / \mathrm{kg}$, i.v. nicotine was ineffective in producing anxiolytic effects in the current conflict test and that the larger $0.06-\mathrm{mg} / \mathrm{kg}$ dose which was effective in the current study did not support reliable runway self-administration performance in our prior study. It would seem then that the positive and negative reinforcing actions of the drug may require different dosing regimens and hence may be related to dissociable actions of nicotine within the nervous system. In this context, individual differences in the acquisition, rate, and preferred dose of nicotine self-administration may be accounted for in part by the underlying motivation of the user and whether the drug is being ingested primarily for its positive or negatively reinforcing nature.

Acknowledgments The authors wish to thank Jennifer Park and Myra A. Llamas for their invaluable assistance with data collection. This work was supported by PHS-NIDA grant DA05041 awarded to A.E.

Open Access This article is distributed under the terms of the Creative Commons Attribution Noncommercial License which permits any noncommercial use, distribution, and reproduction in any medium, provided the original author(s) and source are credited.

\section{References}

Baker TB, Brandon TH, Chassin L (2004) Motivational influences on cigarette smoking. Ann Rev Psychol 55:463-491

Balerio GN, Aso E, Maldonado R (2006) Role of the cannabinoid system in the effects induced by nicotine on anxiety-like behavior in mice. Psychopharmacology 184:504-513 
Biala G, Budzynska B (2006) Effects of acute and chronic nicotine on elevated plus maze in mice: involvement of calcium channels. Life Sci 30:81-88

Biala G, Kruk M (2008) Calcium channel antagonists suppress crosstolerance to the anxiogenic effects of d-amphetamine and nicotine in the mouse elevated plus maze test. Prog Neuropsychopharmacol Biol Psychiatry 1:54-61

Booze RM, Welch MA, Wood ML, Billings KA, Apple SR, Mactutus CF (1999) Behavioral sensitization following repeated intravenous nicotine administration: gender differences and gonadal hormones. Pharmacol Biochem Behav 64:827-839

Brioni JD, O'Neill AB, Kim DJB, Decker MW (1993) Nicotinic receptor agonists exhibit anxiolytic-like effects on the elevated plus-maze test. Eur J Pharmacol 283:1-8

Cao J, Belluzzi JD, Loughlin SE, Keyler DE, Pentel PR, Leslie FM (2007) Acetaldehyde, a major constituent of tobacco smoke, enhances behavioral, endocrine, and neuronal responses to nicotine in adolescent and adult rats. Neuropsychopharmacology 32:2025-2023

Cheeta S, Irvine E, File SE (2001) Social isolation modifies nicotine's effects in animal tests of anxiety. Br J Pharmacol 132:1389-1395

Clarke PB, Kumar R (1983) The effects of nicotine on locomotor activity in non tolerant and tolerant rats. Br J Pharmacol 78:329337

Cohen A, Ettenberg A (2007) Motivation effects of nicotine as measured in a runway model of self-administration. Behav Pharmacol 18:265-271

Corrigall WA, Coen KM (1989) Nicotine maintains robust selfadministration in rats on a limited access schedule. Psychopharmacology 99:473-478

Daughton DM, Roberts D, Patil KD, Rennard SI (1990) Smoking cessation in the workplace: evaluation of relapse factors. Prev Med 19:227-230

De noble VJ, Mele PC (2006) Intravenous nicotine self-administration in rats: effects of mecamylamine, hexamethonium and naloxone. Psychopharmacology 184:266-272

Di Chiara G (2000) Role of dopamine in the behavioral actions of nicotine related to addiction. Eur J Pharmacol 393:295-314

Donny EC, Caggiula AR, Knopf S, Brown C (1995) Nicotine selfadministration in rats. Psychopharmacology 122:390-394

Dwoskin LP, Crooks PA, Teng L, Green TA, Bardo MT (1999) Acute and chronic effects of nornicotine on locomotor activity in rats: altered response to nicotine. Psychopharmacology 145:442-51

Ettenberg A, Bernardi RE (2006) Anxiolytic-like actions of buspirone in a runway model of intravenous cocaine self-administration. Pharmacol Biochem Behav 85:393-399

Ettenberg A, Geist TD (1991) An animal model for investigating the anxiogenic properties of self administered cocaine. Psychopharmacology 103:455-461

Ettenberg A, Geist TD (1993) Qualitative and quantitative differences in the operant runway behavior of cocaine and heroin reinforced rats. Pharmacol Biochem Behav 44:191-198

Feldner MT, Babson KA, Zvolensky MJ (2007) Smoking, traumatic event exposure, and post-traumatic stress: a critical review of the empirical literature. Clin Psychol Rev 27:14-45

File SE, Kenny PJ, Ouagazzal AM (1998) Bimodal modulation by nicotine of anxiety in the social interaction test: role of the dorsal hippocampus. Behav Neurosci 112:1423-1429

Foulds J, Stapleton JA, Bell N, Swettenham J, Jarvis MJ, Russell MA (1997) Mood and physiological effects of subcutaneous nicotine in smokers and never-smokers. Drug Alcohol Depend 14:105-115

Geist TD, Ettenberg A (1997) Concurrent positive and negative goal-box events produce runway behaviors comparable to those of cocaine-reinforced rats. Pharmacol Biochem Behav 57:145150
Geller I, Kulak JT Jr, Seifter J (1962) The effects of chlordiazepoxide and chlorpromazine on a punishment discrimination. Psychopharmacologia 31:374-385

Gilbert DG, Robinson JH, Chamberlin CL, Spielberger CD (1989) Effects of smoking/nicotine on anxiety, heart rate, and lateralization of EEG during a stressful movie. Psychophysiology $26: 311-320$

Glowa JR (1986) Some effects of d-amphetamine, caffeine, nicotine and cocaine on schedule-controlled responding of the mouse. Neuropharmacology 25:1127-1135

Goldberg SR, Spealman RD (1983) Suppression of behavior by intravenous injections of nicotine or by electric shock in Squirrel monkeys: effects of chlordiazepoxide and mecamylamine. J Pharmacol Exp Ther 224:334

Guzman A, Ettenberg A (2004) Heroin attenuates the negative consequences of cocaine in a runway model of selfadministration. Pharmacol Biochem Behav 79:317-324

Harrod SB, Mactutus CF, Bennett K, Hasselrot U, Wu G, Welch M, Booze RM (2004) Sex differences and repeated intravenous nicotine: behavioral sensitization and dopamine receptors. Pharmacol Biochem Behav 78:581-592

Herbert M, Foulds J, Fife-Schaw C (2001) No effect of cigarette smoking on attention or mood in non depressed smokers. Addiction 96:1349-1356

Houser VP (1978) The effects of drugs on behavior controlled by aversive stimuli. In: Blackman DE, Sanger DJ (eds) Contemporary research in behavioral pharmacology. Plenum, New York, pp 69-157

Hughes JR, Gust SW, Skoog K, Keenan RM, Fenwick JW (1991) Symptoms of tobacco withdrawal. A replication and extension. Arch Gen Psychiatry 48:52-59

Irvine EE, Cheeta S, File SE (1999) Time-course of changes in the social interaction test of anxiety following acute and chronic administration of nicotine. Behav Pharmacol 10:691-697

Kassel JD, Paronis CA, Stroud LR (2003) Smoking, stress, and negative affect: correlation, causation, and context across stages of smoking. Psycholl Bull 129:270-304

Knackstedt LA, Ettenberg A (2005) Ethanol consumption reduces the adverse consequences of self-administered intravenous cocaine in rats. Psychopharmacology 178:143-150

Ksir C (1994) Acute and chronic nicotine effects on measures of activity in rats: a multivariate analysis. Psychopharmacology 115:105-109

Lee EH (1985) Effects of nicotine on exploratory behavior in rats: correlation with regional brain monoamine levels. Behav Brain Res 17:59-66

Mansvelder HD, McGehee DS (2002) Cellular and synaptic mechanisms of nicotine addiction. J Neurobiol 53:606-617

McCloskey TC, Paul BK, Commissaris RL (1987) Buspirone effects in an animal conflict procedure: comparison with diazepam and phenobarbital. Pharmacol Biochem Behav 27:171-175

McKennell AC (1970) Smoking motivation factors. Br J Soc Clin Psychol 9:8-22

Merlo Pich E, Chimaulera C, Carboni L (1999) Molecular mechanisms of the positive reinforcing effect of nicotine. Behav Pharmacol 10:587-596

Miller NE (1944) Experimental studies of conflict. In: Hunt J McV (ed) Personality and the behavior disorders. Ronald, New York, pp 431-465

Miller DK, Wilkins LH, Bardo MT, Crooks PA, Dwoskin LP (2001) Once weekly administration of nicotine produces long-lasting locomotor sensitization in rats via a nicotinic receptor-mediated mechanism. Psychopharmacology 156:469-476

Miller DK, Harrod SB, Green TA, Wong MY, Bardo MT, Dwoskin LP (2003) Lobeline attenuates locomotor stimulation induced by 
repeated nicotine administration in rats. Pharmacol Biochem Behav 74:279-286

Montgomery KC (1955) The relation between fear induced by novel stimulation and exploratory behavior. J Comp Physiol Psvchol 48:254-260

Morrison CF (1969) The effects of nicotine on punished behaviour. Psychopharmacologia 14:221-232

Neugebauer NM, Zhang Z, Crooks PA, Dwoskin LP, Bardo MT (2006) Effect of a novel nicotinic receptor antagonist, $N, N^{\prime}$-dodecane-1,12diyl-bis-3-picolinium dibromide, on nicotine self-administration and hyperactivity in rats. Psychopharmacology 184:426-434

Newhouse A, Sunderland T, Narang PK, Mellow AM, Fertig JB, Lawlor BA, Murphy DL (1990) Neuroendocrine, physiologic, and behavioral responses following intravenous nicotine in nonsmoking healthy volunteers and in patients with Alzheimer's disease. Psychoneuroendocrinology 15:471-484

Nichter M, Vuckovic N, Quintero G, Ritenbaugh C (1997) Smoking experimentation and initiation among adolescent girls: qualitative and quantitative findings. Tob Control 6:285-295

Ouagazzal AM, Kenny PJ, File SE (1999) Modulation of behaviour on trials 1 and 2 in the elevated plus-maze test of anxiety after systemic and hippocampal administration of nicotine. Psychopharmacology 144:54-60

Parrott AC (2003) Cigarette-derived nicotine is not a medicine. World J Biol Psychiatry 4:49-55

Perkins KA, Grobe JE (1992) Increased desire to smoke during acute stress. Br J Addict 87:1037-1040

Perkins KA, Sexton JE, Reynolds WA, Grobe JE, Fonte C, Stiller RL (1994) Comparison of acute subjective and heart rate effects of nicotine intake via tobacco smoking versus nasal spray. Pharmacol Biochem Behav 47:295-299

Picciotto MR, Bruzell DH, Caldarone BJ (2002) Effect of nicotine and nicotinic receptors on anxiety and depression. Neuroreport 13:1097-1106

Pomerleau OF, Pomerleau CS (1987) The effects of a psychological stressor on cigarette smoking and on subsequent behavioral and physiological responses. Psychophysiology 24:278-285

Pomerleau OF, Turk DC, Fertig JB (1984) The effects of cigarette smoking on pain and anxiety. Addict Behav 9:265-271
Prut L, Belzung C (2003) The open field as a paradigm to measure the effects of drugs on anxiety-like behaviors: a review. Eur J Pharmacol 463:3-33

Samaha AN, Yau WY, Yang P, Robinson TE (2005) Rapid delivery of nicotine promotes behavioral sensitization and alters its neurobiological impact. Biol Psychiatry 57:351-360

Shram MJ, Funk D, Li Z, Le AD (2006) Periadolescent and adult rats respond differently in tests measuring the rewarding and aversive effects of nicotine. Psychopharmacology 186:201-208

Stolerman IP, Shoaib M (1991) The neurobiology of tobacco addiction. Trends Pharmacol Sci 12:467-473

Tate JC, Pomerleau OF, Pomerleau CS (1993) Temporal stability and within-subject consistency of nicotine withdrawal symptoms. J Subst Abuse 5:355-363

Tessari M, Pilla M, Andreoli M, hutcheson DM, Heidbreder CA (2004) Antagonism at metabotropic glutamate 5 receptors inhibits nicotineand cocaine-taking behaviors and prevents nicotine-triggered relapse to nicotine-seeking. Eur J Pharmacol 499:121-133

Treit D, Fundytus M (1988) Thigmotaxis as a test for anxiolytic activity in rats. Pharmacol Biochem Behav 31:959-962

U.S. Department of Health and Human Services (1988) The health consequences of smoking: nicotine addiction. A report of the Surgeon General. Office on Smoking and Health, Maryland

Vaidya AH, Rosenthal DI, Lang W, Crooke JJ, Benjamin D, Ilyin SE, Reitz AB (2005) Oral buspirone causes a shift in the dose-response curve between the elevated-plus maze and Vogel conflict tests in Long-Evans rats: relation of brain levels of buspirone and 1-PP to anxiolytic action. Methods Find Exp Clin Pharmacol 27:245-255

Vogel JR, Beer B, Clody DE (1971) A simple and reliable conflict procedure for testing anti-anxiety agents. Psychopharmacologia 21:1-7

Walsh RN, Cummins RA (1976) The open-field test: a critical review. Psychol Bull 83:482-504

Warburton DM, Mancuso G (1998) Evaluation of the information processing and mood effects of a transdermal nicotine patch. Psychopharmacology 135:305-310

Watkins SS, Epping-Jordan MP, Koob GF, Markou A (1999) Blockade of nicotine self-administration with nicotinic antagonists in rat. Pharmacol Biochem Behav 60:743-751 